\title{
Vivencias discriminatorias según colombianas y paraguayas radicadas en Ecuador y Brasil
}

\author{
Elizabeth Ruano* \\ Patrícia Nabuco Martuscelli**
}

\section{Introducción ${ }^{1}$}

Según informaciones de la Organización de las Naciones Unidas, en el año 2013 de los 242 millones de inmigrantes internacionales las mujeres representaron un porcentaje de $48 \%$ colocando en destaque el fenómeno de la feminización de las migraciones. Sin embargo, ese número no revela las especificidades de esa dinámica social, las privaciones y probaciones que las inmigrantes enfrentan todos los días para realizar sus proyectos migratorios. Con el objetivo de analizar esa situación, en este artículo se retoman las respuestas de migrantes colombianas y paraguayas que migraron a Ecuador y Brasil, respectivamente buscando explorar la sobre posición de situaciones de discriminación, principalmente por razones de género y estatus migratorio.

Los datos empíricos aquí analizados provienen del proyecto de investigación "Mujer Migrante: Agente de resistencia y transformación", realizado por el Centro Scalabriniano de Estudios Migratorios (CSEM), entre 2011 a 2012². Esa investigación buscó destacar la transversalidad de las dimensiones afectiva, profesional y social en los proyectos migratorios. Al privilegiar a las mujeres como sujeto de investigación se asumió la centralidad de la dimensión de género, como principio clasificatorio que, en conjunto con otras categorías, configura y atraviesa las vivencias migratorias (CSEM, 2014). Esa dimensión también será determinante para analizar la inserción laboral, puesto que las migrantes son reclutadas para tareas específicas en el marco de la división internacional del trabajo (DUTRA, 2013b).

Las inmigrantes que participaron de ese proyecto fueron contactadas por integrantes de la comunidad Scalabriniana, esa opción buscó facilitar la accesibilidad y explorar el vínculo de confianza pre-existente en el ámbito del

\footnotetext{
* Doctora en Ciencias Sociales. Profesora Visitante CEPPAC-UnB. E=mail: elizabeth@unb.br

** Candidata a doctora en Ciencia Política en la Universidad de São Paulo. Becaria CAPES. E=mail: patnabuco@gmail.com
} 
trabajo socio pastoral (DUTRA, 2013b). La recolección de la información fue mediada por la aplicación de un cuestionario integrado por preguntas abiertas (82\%) y cerradas (18\%) sobre la familia, el trabajo, el acceso a servicios públicos en el país de destino, las políticas migratorias en origen y destino y las posibilidades de retorno. Los cuestionarios fueron aplicados por diferentes investigadores en cada caso (DUTRA, 2013a).

El análisis que aquí se presenta se construyó a partir de las respuestas ofrecidas por 43 inmigrantes, de las cuales 20 con paraguayas radicadas en São Paulo (Brasil) y 23 con colombianas radicadas en las ciudades de Quito, Ibarra, Lago Agrio y San Lorenzo (Ecuador $\left.{ }^{3}\right)$. Se adoptó un recorte temático a partir de las respuestas para las siguientes preguntas: ¿ser mujer y extrajera dificulta encontrar un empleo? ¿Usted se siente discriminada en su trabajo por ser mujer extranjera? Además de otras afirmativas para preguntas como: ¿cuáles dificultades encuentra al buscar empleo? y ¿qué le diría a una persona que planea migrar?

Sobre el perfil de las migrantes colombianas, se observó que ninguna se declaró analfabeta, $56 \%$ declararon los siguientes niveles de escolaridad: $26 \%$ declararon poseer educación superior completa, $17 \%$ solamente bachillerato y $13 \%$ solo básica primaria. El $44 \%$ restante declaró haber interrumpido sus estudios, es decir no concluyeron su formación escolar. $57 \%$ de las informantes se encuadraban en el rango de 20 a 30 años de edad. Entre 31 a 40 y 41 a 50 años, $17 \%$ y $17 \%$ respectivamente. En el rango de 51 a 60 años, se ubican $9 \%$ del total.

Cuadro 1. Análisis comparado del perfil de las informantes: edad y escolaridad - porcentaje (\%)

\begin{tabular}{|c|c|c|c|c|c|c|c|c|}
\hline \multirow{2}{*}{ Nacionalidad } & \multicolumn{4}{|c|}{ Rango de edad } & \multicolumn{3}{c|}{ Escolaridad (completo) } \\
\cline { 2 - 9 } & Menos de 18 & $19-30$ & $31-40$ & $41-50$ & +50 & Primaria & Secundaria & Superior \\
\hline Colombia & - & $57 \%$ & $17 \%$ & $17 \%$ & $9 \%$ & $13 \%$ & $17 \%$ & $26 \%$ \\
\hline Paraguay & $10 \%$ & $90 \%$ & & & & $35 \%$ & $45 \%$ & $20 \%$ \\
\hline
\end{tabular}

Fuente: elaboración propia

Entre las informantes paraguayas, 20\% declararon poseer educación superior completa, $45 \%$ solamente bachillerato completo y $35 \%$ solo básica primaria completa. $90 \%$ se encontraban entre 20 y 30 años de edad, $10 \%$ declararon ser menores de edad, con 17 años. Ese dato confirma la tendencia destacada en las migraciones femeninas paraguayas, formada principalmente por mujeres jóvenes menores de 30 años. Del total de migrantes paraguayos en el mundo, 55\% son mujeres menores de 25 años (DUTRA, 2013a). Comparando el rango de edad entre las inmigrantes colombianas y paraguayas se observa la 
concentración de estas últimas entre menos de 18 hasta 30 años. De otro lado, entre las colombianas se observa que se distribuyen mejor en otros intervalos de edad, sin embargo, el porcentaje también es mayor en el rango entre 19 a 30 años, alcanzando un total de $57 \%$.

La relevancia del análisis presentado en este artículo puede ser justificada en dos niveles. En primer lugar, las afirmativas individuales ofrecidas por las inmigrantes en estudio ganan otros contornos, de significado y merecimiento, cuando son analizadas conjuntamente, aspecto que permite proyectar el debate y superar los límites de los casos estudiados. En segundo lugar, conviene destacar la contribución de los casos singulares para la comprensión de feminización de las migraciones internacionales como fenómeno universal. La bibliografía (SALA, 2005; CORTES y SILVA, 2014; PROFIT, 2015; BENALCAZAR, 2004; ORTIZ y KAMINKER, 2015) explorada en los siguientes ítems, mostró que la feminización de la pobreza es un fenómeno relevante en Colombia y Paraguay, datos oficiales indican porcentajes significativos de 30 y $55 \%$ respectivamente.

Este artículo se divide en cuatro secciones, incluyendo la introducción y la conclusión. La primera sección revisa conceptualmente la discriminación negativa en dialogo con una breve revisión de los instrumentos de Derecho Internacional que abordan la temática de la discriminación contra las mujeres migrantes. La tercera sección analiza comparativamente las respuestas obtenidas y enfatiza las modalidades de discriminación vivenciadas por inmigrantes colombianas y paraguayas que participaron de la investigación ya mencionada.

\section{Breve revisión conceptual: discriminación negativa y mujeres inmigrantes}

En los estudios sobre discriminación se destacan dos tipos: la positiva y la negativa (CASTEL, 2008). La primera basada en la inclusión, defiende políticas de tratamiento diferenciado con base en características y atributos individuales o colectivos. Tiene por presupuesto que las personas objeto de esas políticas puedan acceder en condiciones de equidad a los mismos derechos garantizados a las personas o grupos que no tienen necesidad de ese tratamiento especial. Por otro lado, la discriminación negativa se sustenta en prejuicios, estereotipos y estigmas hacia ciertas particularidades identitárias del otro, sean individuos o grupos sociales.

Según Castel (2008), la discriminación negativa ${ }^{4}$ marca a sus víctimas, de modo casi indeleble, como poseedoras de defectos que los tornan objeto de estigmatización. Ser discriminado negativamente significa ser asociado a un destino que toma como base una característica que no se eligió, pero que el otro la acciona en la forma de un estigma. La discriminación negativa es la instrumentalización de la alteridad y opera mediante tratamientos diferenciados para descalificar. Constituida en favor de la exclusión y calcada en la desigualdad, se alimenta de estereotipos y prejuicios. Entre los inmigrantes es conocido el imaginario que los torna "chivos expiatorios" y los encuadra como 'enemigos' 
de la seguridad nacional, 'ladrones' de empleos y 'causantes' del crecimiento de la violencia y del desempleo. Esos prejuicios acentúan las condiciones de vulnerabilidad de esos grupos minoritarios en contextos nacionales.

La discriminación negativa mantiene diferenciaciones injustas y arbitrarias, a veces constantes en el tiempo y que pueden traducirse en impedimentos para la interacción social entre aquellos considerados iguales y los diferentes. Las acciones materiales o intelectuales que incentivan el trato discriminatorio pueden presentarse en momentos específicos, pudiendo, la mayoría de las veces limitarse a comentarios, actitudes o expresiones negativas. En algunos casos, la persona discriminada no logra siquiera percatarse o asumirse como víctima de esas prácticas (SÁNCHEZ; HERNÁNDEZ; PÉREZ, 2007).

Las mujeres inmigrantes sufren discriminación negativa por condiciones de estatus migratorio, género, cultura, religión, idioma, nacionalidad y fenotipo. Esa vulnerabilidad en contextos migratorios es agudizada por las dificultades para regularizar su estatus en los países de destino. Migrantes en situación irregular se constituyen en albos principales de discursos y acciones xenofóbicos Conforme organizaciones internacionales (ILO; IOM; ORCHR, 2001), la situación irregular incide en que los abusos y la discriminación no sean denunciados, manteniéndose invisible e imposibilitando la generación de estrategias de mitigación.

Las respuestas de las migrantes paraguayas y colombianas permiten constatar que sus experiencias migratorias son atravesadas por diferentes tipos de discriminación. El sufrimiento de esos diferentes tipos por una sola persona puede ser mejor comprendido a partir del concepto de interseccionalidad (CRENSHAW, 2004; DUTRA, 2013b). El cruzamiento de clase, género, origen social y étnico permite problematizar que las trabajadoras inmigrantes son más vulnerables socialmente en comparación con las mujeres nativas y los hombres inmigrantes.

Parella (2003) enfatizó la discriminación sufrida por las mujeres inmigrantes en las sociedades de destino definiéndola en términos comparativos y revelando una brecha significativa entre los patrones de vida de las mujeres autóctonas y de las migrantes. En ese estudio, variables de clase, género y etnicidad afectan negativamente la vinculación de las migrantes al mercado de trabajo. Esos condicionantes, conjugados con el acceso desigual a recursos materiales, conforman un ciclo que nutre y perpetúa la vulnerabilidad femenina en contextos migratorios.

Según el informe del Comité de las Naciones Unidas para la Eliminación de la Discriminación contra la Mujer (CEDAW, sigla en inglés), la discriminación se nutre de las directrices de las políticas inmigratorias restrictivas. Los discursos y acciones gubernamentales que clasifican a los inmigrantes como 'ilegales' o 'criminosos' refuerzan el encuadramiento común como sospechosos que amenazan la seguridad de los Estados nacionales. Ese informe también destacó que mujeres y hombres inmigrantes sufren la discriminación de maneras diferenciadas (CEDAW, 2008). 
Dicho informe caracterizó la vulnerabilidad enfrentada por las mujeres inmigrantes revelando que ellas enfrentan mayores restricciones para obtener informaciones sobre migraciones internacionales, derechos y deberes en los países de destino. Algunos gobiernos aún imponen restricciones para el acceso femenino a determinados empleos, basándose en los roles tradicionales femeninos inaugurados por la división internacional del trabajo basada en la desigualdad de género. Esas prácticas actualizan la violencia de género, la feminización dela pobreza y del mercado migratorio (CEDAW, 2008).

Adicionalmente los ambientes de trabajo generalmente no son sensibles a las situaciones de género y niegan la movilidad profesional a las mujeres. Los sectores que demandan fuerza de trabajo femenina ofrecen alto riesgo a sufrir diferentes formas de abuso. El trabajo doméstico, de cuidado y algunas formas de entretenimiento en el mercado informal, tienden a ignorar las protecciones legales del trabajo, es decir no garantizan derechos o protección social. La discriminación contra las trabajadoras migrantes se traduce también, en algunos casos, en salarios menores, inclusive algunas no son remuneradas, otras reciben salarios en atraso o solamente mediante la intervención de un hombre familiar (CEDAW, 2008).

Las trabajadoras inmigrantes son más vulnerables a violencia física, abusos y asedios sexuales en el ambiente de trabajo. La inserción de las trabajadoras domésticas ofrece mayor vulnerabilidad a abusos físicos, tratamientos crueles, privación del sueño y de alimentos y limitadas a espacios precarios e insalubres. El asedio sexual contra las migrantes que trabajan en haciendas e industrias es un fenómeno observado en todo el mundo. Inmigrantes en situación irregular son particularmente vulnerables porque su estatus migratorio exacerba el riesgo y potencializa situación de discriminación (CEDAW, 2008).

De la mano de los abusos sexuales se evidencia riesgos de salud a los cuales los hombres migrantes están expuestos en menor grado. Por tanto, ellas necesitan servicios de salud reproductiva que no siempre son gratuitos y que la mayoría no pueden pagar. Adicionalmente el no dominio del idioma local, los costumbres diferentes o el estatus migratorio son causas de discriminación cuando demanda servicios de salud. El embarazo puede constituir una razón para perder el empleo, sin garantía de sus derechos laborales. Se conocen casos de abortos coercitivos o provocados por ausencia de servicios de salud oportunos. En algunos países, mujeres migrantes pueden ser forzadas a hacer pruebas de embarazo y en caso positivo ser deportadas (CEDAW, 2008).

De acuerdo con Gutierrez (2014), las diferentes formas de discriminación negativa sostienen injusticias, indignidades, jerarquías, dominaciones y opresiones. En respuesta a la amplitud perversa de la discriminación y de los múltiples factores de riesgo, la comunidad internacional promulgó algunos instrumentos en el ámbito del Derecho Internacional. El reconocimiento oficial de esos tratados internacionales es importante porque defiende los derechos de todos los seres humanos independientemente de su estatus migratorio. En 
seguida se abordan brevemente los alcances y limitaciones de esos instrumentos en los países objeto de este trabajo, Colombia, Paraguay, Ecuador y Brasil.

El principio de derechos independientemente del estatus migratorio nortea los tratados que se describen en seguida: convención sobre la eliminación de todas las formas de discriminación contra la mujer (CETFDCM), de 1979; Convenio $n^{\circ} 97$ de 1949 relativo a los trabajadores migrantes; Convención sobre el Estatuto de los Refugiados de 1951 y la Convención internacional sobre la protección de los derechos de todos los trabajadores migratorios y de sus familiares de 1990.

El siguiente cuadro muestra comparativamente a los cuatro países, de origen y destino de las migrantes en estudio. Se observa que Ecuador firmó los cuatro tratados en análisis. Colombia y Paraguay no son signatarios de la Convención no 97. Brasil aún no es signatario de la Convención internacional sobre la protección de los derechos de todos los trabajadores migratorios y de sus familiares. Importante destacar que la distancia entre las fechas de promulgación en el ámbito internacional y la posterior ratificación nacional sugiere tensiones y barreras, de naturaleza política, económica y burocrática, principalmente, en torno de los procesos de validación de dichas normativas en los ámbitos nacionales. Esos entrabes deben ser colocados en relevancia para analizar la persistencia de los desafíos en relación al impacto de dichos tratados.

La revisión sumaria aquí descrita destaca que los tratados internacionales defienden como presupuesto que la adhesión, mediante la firma, de los países miembros crea un ambiente favorable para impactar significativamente el fenómeno de la discriminación experimentada por los inmigrantes en general y por las mujeres en particular. Sin embargo, es un hecho que un fenómeno de tal magnitud no se supera apenas con ese tipo de estrategia. Los límites de dichos tratados colocan en destaque desafíos mayores como los entrabes de la acción estatal para garantizar derechos ciudadanos a los migrantes.

Cuadro 2. Países signatarios de los tratados internacionales sobre migración femenina

\begin{tabular}{|l|c|c|c|c|}
\hline \multicolumn{1}{|c|}{ País } & \multicolumn{4}{|c|}{ Tratados internacionales } \\
\hline & $\begin{array}{c}\text { Convención } \mathrm{n}^{\circ} \\
97, \text { relativa a } \\
\text { los trabajadores } \\
\text { migrantes } \\
(1949) .\end{array}$ & $\begin{array}{c}\text { Convención sobre } \\
\text { el Estatuto de los } \\
\text { Refugiados (1951) }\end{array}$ & $\begin{array}{c}\text { Convención sobre } \\
\text { la eliminación de } \\
\text { todas las formas de } \\
\text { discriminación contra la } \\
\text { mujer (1979). }\end{array}$ & $\begin{array}{c}\text { Convención internacional } \\
\text { sobre la protección de } \\
\text { los derechos de todos los } \\
\text { trabajadores migratorios y } \\
\text { de sus familiares (1990) }\end{array}$ \\
\hline Brasil & 1965 & 1960 & 1984 & - \\
\hline Colombia & - & 1961 & 1982 & 1995 \\
\hline Ecuador & 1978 & 1955 & 1981 & 2002 \\
\hline Paraguay & - & 1970 & 1987 & 2008 \\
\hline
\end{tabular}

Fuente: elaboración propia. 
En los tratados aquí analizados el termino discriminación destaca fenómenos sociales dinámicos que remiten al sentido ofensivo y de menosprecio en situaciones históricamente definidas. La Declaración Universal de los Derechos Humanos (1948) refirió ese término de manera pionera, enriqueciéndolo al destacar el trato desigual, las causas que la originan y la diversidad de consecuencias que genera. Los cuatro tratados internacionales aquí citados constituyen un importante avance, un marco de referencia para todos los países. Sin embargo, solamente lograrán potencializar sus efectos si los países signatarios direccionan esfuerzos para defender y aplicar dichas reglamentaciones.

La CEDAW (2008) es uno de los tratados de derechos humanos más ratificado en el mundo, actualmente cuenta con 189 Estados partes. Brasil es signatario desde el 1 o de febrero de 1984, Colombia desde el 19 de enero de 1982, Ecuador desde el 9 de noviembre de 1981 y Paraguay desde el 6 de abril de $1987^{5}$. En su artículo 1 ${ }^{\circ}$, define como discriminación toda distinción, exclusión o restricción basada en el sexo que tenga por objeto o resultado menoscabar o anular el reconocimiento, goce o ejercicio por la mujer, independientemente de su estado civil, sobre la base de la igualdad del hombre y la mujer, de los derechos humanos y las libertades fundamentales en las esferas política, económica, social, cultural y civil o en cualquier otra esfera.

Este convenio obliga a los Estados signatarios a adoptar medidas concretas para eliminar la discriminación contra las mujeres nacionales e inmigrantes, independientemente de su estatus migratorio. Por eso, tiene el potencial de garantizar derechos adicionales para las trabajadoras migrantes. En el artigo 6으, expresa que los Estados firmantes tomaran todas las medidas para "suprimir todas las formas de trata de mujeres y explotación de la prostitución de la mujer". El artículo 11ㅇo orienta hacia "eliminar la discriminación en la esfera del empleo a fin de asegurar a la mujer, condiciones de igualdad con los hombres". El artículo 12 o ordena "eliminar la discriminación contra la mujer en la esfera de la atención médica". El artículo $13^{\circ}$ dictamina "eliminar la discriminación contra la mujer en otras esferas de la vida económica y social". Todas esas recomendaciones se aplicadas facilitarían la integración de las mujeres migrantes en las sociedades de destino.

El Convenio $n^{\circ} 97$ de 1949, en el ámbito de la Organización Internacional del Trabajo (OIT), constituye el primer marco internacional más específico sobre esa temática. Prohíbe la discriminación contra los inmigrantes con respecto a nacionalidad, raza, sexo o religión. Aborda asuntos como remuneración, pensiones, horas de trabajo extra, vacaciones remuneradas, salario mínimo, restricción para llevar trabajo para casa, aprendizaje y capacitación, seguridad social, impuestos, tasas, contribuciones y procedimientos legales. Brasil lo ratificó el 18 de junio de 1965 y Ecuador el 05 de abril de 1978. Colombia y Paraguay no son signatarios de esa Convención ${ }^{6}$, no en tanto, estas normativas se aplican a nacionales de estos países que viven en Estados partes como Brasil e Ecuador. 
La Convención sobre el Estatuto de los Refugiados de 1951 está basada en dos principios: la no devolución de las personas a los lugares donde sus vidas y libertades estaban amenazadas y la no discriminación entre nacionales y refugiados o solicitantes de refugio. Los Estados signatarios se comprometen a combatir, en su territorio nacional, cualquier forma de discriminación contra los refugiados. El artículo 3 reza: "los Estados Contratantes aplicarán las disposiciones de esta Convención a los refugiados, sin discriminación por motivos de raza, religión o país de origen". Este tratado internacional fue ratificado por Brasil el 16 de noviembre de 1960, por Colombia el 10 de octubre de 1961, por Ecuador el 17 de agosto de 1955 y por Paraguay el 10 de abril de 1970.

La Convención internacional sobre la protección de los derechos de todos los trabajadores migratorios y de sus familiares de 1990 objetiva garantizar protección contra todas las formas de racismo y xenofobia. Este tratado entiende a los trabajadores migrantes como entidades sociales con familias y derechos que están desprotegidos en los países de tránsito o de destino. Pretende prevenir y eliminar la explotación, estipulando estándares mínimos de protección que deben ser garantizados por los Estados signatarios. El artículo 7ํairma que:

Los Estados Partes se comprometerán, de conformidad con
los instrumentos internacionales sobre derechos humanos,
a respetar y asegurar a todos los trabajadores migratorios
y sus familiares que se hallen dentro de su territorio o
sometidos a su jurisdicción los derechos previstos en la
presente Convención, sin distinción alguna por motivos
de sexo, raza, color, idioma, religión o convicción, opinión
política o de otra índole, origen nacional, étnico o social,
nacionalidad, edad, situación económica, patrimonio,
estado civil, nacimiento o cualquier otra condición.

El artículo 25ㅇ prohíbe la discriminación en el mercado de trabajo indicando que "los trabajadores migratorios gozarán de un trato que no sea menos favorable que el que reciben los nacionales del Estado en lo tocante a empleo, remuneración y a otras condiciones de trabajo". Los artículos $43^{\circ}$ y $46^{\circ}$ garantizan que los trabajadores migratorios y sus familiares gozarán de igualdad de trato en relación al acceso a educación, servicios sociales, de salud, vida cultural y participación. Según el artículo $67^{\circ}$, los Estados deben proveer sanciones contra personas o grupos que usen violencia contra los trabajadores migrantes y sus familiares, que los empleen en condiciones irregulares, los amenacen o los intimiden. Tres de los cuatro países objeto de este artículo adoptaron esta Convención, Colombia (desde el 24 de mayo de 1995), Ecuador (desde el 5 de febrero de 2002) y Paraguay (desde el 23 de septiembre de 2008). Brasil aún no la ha ratificado.

Conviene destacar que los instrumentos internacionales aquí citados definen la discriminación como distinciones u omisiones que imposibilitan, 
directa o indirectamente, de manera deliberada o no, el ejercicio igualitario de los derechos humanos y de las libertades fundamentales en la vida civil, política, social, económica o cultural. Tal comprensión es fundamental para insistir en la relación entre discriminación y vulnerabilidad de las mujeres migrantes.

Desde los años 1970, es creciente el número de mujeres que migran al exterior en busca de mejores oportunidades y empleos. En 2005, más de 90 millones de mujeres se encontraban en países distintos a su lugar de origen (CALAVITA, 2006). Según Dutra (2013b), la feminización de las migraciones internacionales puede ser explicada a partir de los siguientes factores: primero, los cambios demográficos. Segundo, la inserción de las mujeres en el mercado de trabajo que condujo a la delegación de las actividades domésticas y de cuidado, principalmente, en las trabajadoras inmigrantes. Tercero, la presión poblacional, el desempleo y las crisis económicas. Cuarto, la formación de redes migratorias intencionales basadas en lazos de familia, cultura e historia. Según la CEDAW (2008), la violencia de género, los desastres naturales y los conflictos armados también incentivan las migraciones femeninas.

Assis y Kosminsky (2007) argumentan que las migraciones femeninas son invisibilizadas en los estudios migratorios donde la categoría migrante es teóricamente género-neutra. Así los estudios sobre mujeres migrantes no deben apenas mostrar como ellas contribuyen económica y socialmente para sus hogares y países de origen, más también que el proceso migratorio cambia las relaciones, identidades y discursos de género. El análisis de las respuestas de las inmigrantes en cuestión invita a que las entendamos como agentes de su proceso migratorio a pesar del género ser una categoría que motiva la discriminación en dichos contextos.

Como trabajadoras migrantes, contribuyen significativamente en la composición del ingreso familiar, colocando en relieve cierta redefinición de su lugar en las relaciones familiares y de género. Esas reconfiguraciones revelan la centralidad de las remesas económicas en los proyectos migratorios femeninos y la vulnerabilidad de las mujeres que, en muchos casos, aceptan empleos y salarios precarios para garantizar sus ingresos (BOTEGA; RUANO, 2015). Esas variables las condicionan a aceptar trabajos abusivos demarcando su experiencia migratoria en la vulnerabilidad (DUTRA, 2013b).

Para los objetivos de este artículo, conviene citar que las profesiones ocupadas por las migrantes latinas, en origen y destino, se insieren en el sector terciario. Principalmente en el segmento de cuidados - empleadas domésticas; babas; cuidadoras de ancianos - y servicios, y en menor proporción en la industria y agricultura (VILELA; NORONHA, 2013). El sector terciario como espacio laboral es marcadamente heterogéneo, coexisten segmentos que ofrecen condiciones laborales dignas y los llamados de "supervivencia" - comercio y servicios personales - por su acentuada precarización. Esas evidencias remiten a otros fenómenos sociales como la tercerización del mercado de trabajo, el envejecimiento de la población y el crecimiento de los servicios de cuidado (ARIZA, 2008). 
Dutra (2013b) defiende que la división internacional y sexual del trabajo ofrece una salida mediante la mercantilización de las tareas domésticas y de cuidado. Pero dicha alternativa es simultáneamente una encrucijada que niega a las mujeres oportunidades de formación, educación y de movilidad social en los países de destino. Por un lado, es evidente la inserción de las mujeres migrantes en empleos que no están disponibles para los hombres migrantes. En ese sentido, las migraciones pueden presentarse como oportunidades de empoderamiento económico y participación social para las inmigrantes.

\section{Vivenciando la discriminación a partir de la perspectiva de inmigrantes colombianas y paraguayas}

Para contextualizar el análisis de las respuestas en cuestión se presenta una breve revisión de los flujos migratorios en estudio, Paraguay-Brasil y Colombia-Ecuador. La migración paraguaya para el Brasil se remonta al siglo XIX, configurándose como uno de los grupos pioneros de inmigrantes latinoamericanos (PERARO, 2003). El gobierno Solano López (1827-1870) y los contextos sociopolíticos de la segunda mitad de ese siglo, destaque para la Guerra de la Triple Alianza, demarcan la inmigración con repercusiones que alcanzaron al siglo XX. Según Profit (2015), las trayectorias migratorias que circulan entre esos dos países se inscriben en dinámicas de flujos y contra flujos, en escala local, regional, nacional y transnacional.

En el Censo brasileño (IBGE, 2000), 61.357 personas declararon nacionalidad paraguaya. Según Sala (2005), en el año 2000, la inmigración paraguaya hacia Brasil fue equivalente al $27,8 \%$ del total de inmigración procedente de países del Cono Sur. En 1980, ese porcentaje era de 17,5 \%. Para el año 2010, el consulado de Paraguay estimó un total de $\mathbf{2 0 0}$ mil paraguayos radicados en Brasil. Datos de la Organización Internacional para las Migraciones (OIM) revelan que, en 2011, $12 \%$ de la populación paraguaya había emigrado. Brasil y Estados Unidos se ubican como el tercer ${ }^{7}$ destino, recibiendo menos de $10 \%$ del total de los inmigrantes paraguayos. Conforme Zavattiero (2013), entre 2009 a 2013, 55\% del total de inmigrantes paraguayos eran mujeres jóvenes, en su mayoría, provenientes del área rural ${ }^{8}$.

Cortes y Silva (2014) afirman que la dinámica reciente de la inmigración paraguaya hacia Brasil es impulsada por la demanda de mano de obra de la industria de confección, particularmente en São Paulo y su región metropolitana. Los autores destacan los siguientes elementos como factores que incentivan la inmigración paraguaya: relativa facilidad para ingresar en Brasil; bajo costo y mínimo riesgo para cruzar la frontera, oportunidades de empleo en el sector de confección, que, en algunos casos, ofrece hospedaje y alimentación. En el año 2009 , los inmigrantes paraguayos con estatus migratorio irregular se consolidaron como la cuarta nacionalidad con mayor número de procesos regularizados en el ámbito del Proyecto de Ley no 1.664/07 o Ley de Amnistía Migratoria (Ley ${ }^{\circ}$ 11.961) aprobada en 2009. 
Según Sala (2005), la vulnerabilidad de las inmigrantes paraguayas remite a su baja escolaridad y a su inserción en empleos de mala calidad, principalmente en el sector de trabajo doméstico y como vendedoras en el sector de comercio. De acuerdo con Vilela (2011), en el mercado de trabajo brasileño, los migrantes latinos encuentran mayores desventajas en comparación con los trabajadores nativos blancos. Los paraguayos, en particular, enfrentan condiciones de trabajo peores en relación a los trabajadores brasileros en general.

Según Profit (2015), las particularidades socioeconómicas de cada núcleo familiar orientan la negociación de responsabilidades en los proyectos migratorios de los paraguayos que migran para Brasil. Condicionantes de orden sociodemográfico como edad, género, escolaridad, experiencia laboral y migratoria se tornan dispositivos que determinan la función de cada miembro familiar en el emprendimiento de inmigración. Los acuerdos construidos por esas familias entorno de la inmigración, en primer lugar, buscan incrementar el ingreso familiar. Adicionalmente determinan responsabilidades en lo relacionado al cuidado de los niños y ancianos, en origen, y a establecer estrategias de apoyo en el local de destino.

De otro lado, la historia del flujo migratorio entre Colombia y Ecuador se encuadra en relaciones dinámicas en torno de la frontera. Del lado colombiano está compuesta por los departamentos de Nariño y Putumayo. Las provincias de Esmeraldas, Carchí y Sucumbíos conforman el trecho ecuatoriano. De acuerdo con Morales, Wing-Ching y Acuña (2010), esa línea divisoria recorta un conjunto de unidades geográficas estratégicas de reproducción social que superan la demarcación internacional territorial. A partir de una perspectiva económica se observa un rezago, principalmente del lado colombiano. En el lado ecuatoriano, en la provincia de Sucumbíos, se encuentran los principales yacimientos petroleros, primer recurso nacional, y el Oleoducto Transandino que recorre 306 Km., desde Lago Agrio (Ecuador) hasta el puerto de Tumaco (Colombia).

El flujo de migrantes en la frontera entre Colombia y el Ecuador está atravesado por factores de naturaleza geográfica, sociopolítica y económica. Según Benalcázar (2004), esos migrantes son generalmente afectados por las fumigaciones del Plan Colombia, perseguidos por los actores armados, desplazados internos que lo han perdido todo, incluso a sus familiares, otros huyen del reclutamiento forzoso de los menores de edad o proceden de familias rotas por los fenómenos antes citados. Esos migrantes proceden, mayoritariamente, del área rural de los departamentos colombianos del sur, fronterizos con el territorio ecuatoriano.

Ortiz y Kaminker (2015) afirman que las migraciones forzadas de colombianos, en los últimos treinta años, están íntimamente relacionadas con la violencia política del país. El periodo entre 1996 a 2005 fue marcado por el despoblamiento de territorios tildados como de influencia guerrillera, la expansión del paramilitarismo y el narcotráfico. A partir del 2006, ganó relevancia la consolidación del paramilitarismo, la criminalización y persecución contra 
defensores de derechos humanos y opositores políticos. En 2008, la OIM registró que $9 \%$ de la población, equivalente a 4.167 .388 colombianos, se encontraba en el exterior (OIM, 2015).

En ese contexto, la migración forzada de colombianos apareció como un fenómeno masivo hacia varios países, incluidos los de Suramérica. Al final de la década de los noventa, los países de Suramérica no figuraban como destino para los refugiados colombianos, sin embargo, esa situación cambió en la década de 2000. Actualmente América del Sur recibe aproximadamente $80 \%$ de los refugiados colombianos. En los primeros años del nuevo siglo, se registraron desplazamientos masivos entre las fronteras internacionales de Venezuela y Ecuador, el primero recibe $52 \%$ y el segundo $32 \%$ del total de refugiados colombianos. El 33\% de personas en tal situación son mujeres (ACNUR, 2013). La migración forzada entre esas fronteras se asemeja a las dinámicas del desplazamiento forzado interno, principalmente, de personas en condiciones socioeconómicas vulnerables y opositores al régimen económico y político colombiano (ORTIZ; KAMINKER, 2015).

En el perfil de los colombianos solicitantes de refugio en Ecuador, sobresalen las mujeres cabeza de familia con varios hijos provenientes del área rural colombiana. Esas personas se localizan, principalmente, en las provincias de frontera y centros urbanos en el centro, occidente y sur de Ecuador. Esa tendencia fue ratificada por las colombianas que participaron de esta pesquisa, las cuales estaban localizadas en provincias fronterizas de Pichincha, Imbabura, Sucumbius y Esmeraldas. Los barrios urbanos marginales con costos menores de arriendo y menos servicios públicos son los locales que abrigan a los refugiados colombianos. Ventas ambulantes, oficios domésticos, labores artesanales y construcción civil son las actividades productivas de la economía informal en las que con mayor frecuencia se insieren los refugiados. Sin embargo, la mayoría se encuentra desempleada. La prohibición laboral para los solicitantes de refugio, la crisis económica y el desempleo en Ecuador, la imposibilidad de encontrar oficios afines a la vocación agrícola predominante en esos refugiados, la discriminación social y laboral de que son objeto los colombianos son factores que dificultan dicha inserción laboral (BENALCÁZAR, 2004).

Esta contextualización sirve no solamente como paño de fondo para el análisis de las afirmativas ofrecidas por las inmigrantes que participaron de la investigación, ese contexto es fundamental para entender la complejidad de esos procesos migratorios. La gráfica 1, elaborada a partir de los datos empíricos de las entrevistas con las inmigrantes, indica que $4,7 \%$ y $2,3 \%$ de las entrevistadas, respectivamente, han experimentado situaciones en las cuales la discriminación por género incidió negativamente en la inserción en el mercado de trabajo en Ecuador y Brasil. Según relataron, se sintieron discriminadas cuando percibieron que los empleadores prefieren contratar a los hombres inmigrantes. La segregación ocupacional por género es un factor que dificulta la inserción de las mujeres inmigrantes en el mercado de trabajo. El $41 \%$ de las colombianas 
y $10 \%$ paraguayas se encontraban sin empleo durante la realización de las entrevistas, en 2012. Las entrevistadas también desempeñaban, en sus países de origen, actividades históricamente calificadas como pertenecientes al universo femenino. Se sabe, que esa identidad profesional femenina (DUTRA, 2013b) es demarcada por la división internacional y sexual de trabajo.

Gráfica 1. Comparación a partir de las respuestas sobre discriminación por género y nacionalidad

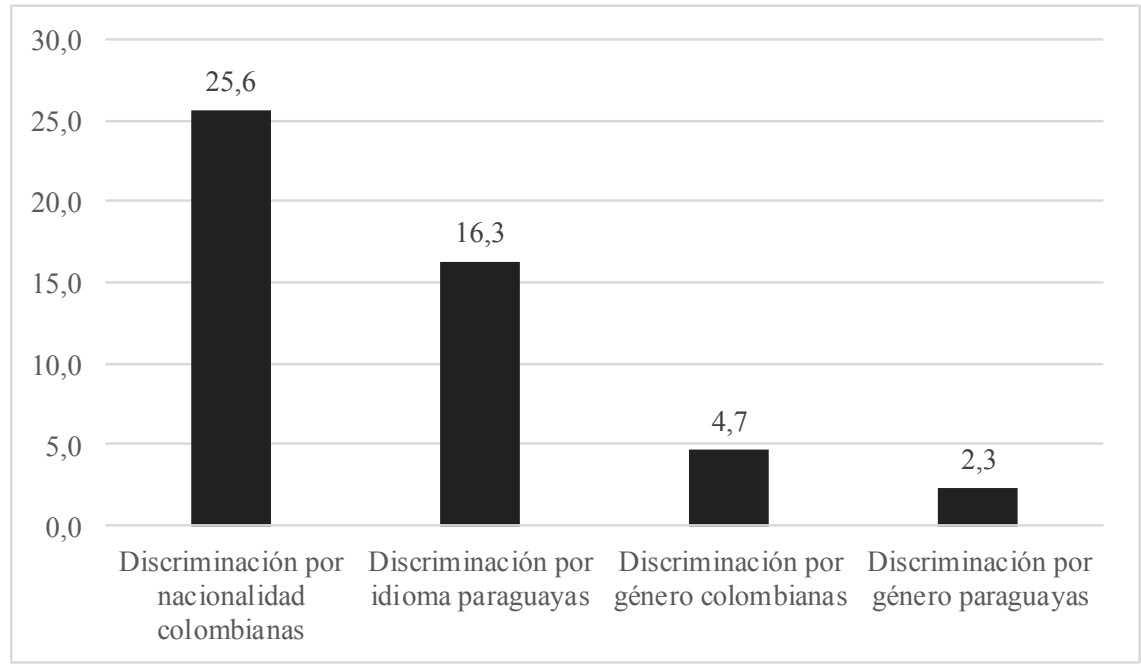

Fuente: elaboración propia a partir de las entrevistas

La gráfica 1 muestra la incidencia de la discriminación lingüística y por nacionalidad. Entre las colombianas, el $25,6 \%$ se sienten discriminadas por su origen nacional. Afirman que no las contratan por ser colombianas o si las contratan no les reconocen su salario. Benalcázar (2004) evidenció la predominancia, entre los ecuatorianos, de un imaginario estereotipado en relación a la nacionalidad colombiana. Según este autor, en Ecuador, ese imaginario es constantemente estimulado por el discurso oficial y reforzado por líderes de opinión en los medios de comunicación, principalmente en la televisión. Un porcentaje de $30 \%$ de las colombianas manifestaron que desean trabajar en actividades afines con su formación escolar, sin embargo, no logran el reconocimiento de sus diplomas en Ecuador. La validación de diplomas es una limitante que dificulta su inserción en diferentes esferas de la vida social en el país de destino.

Un porcentaje equivalente al $16,3 \%$ de las entrevistadas paraguayas declaran haber experimentado discriminación lingüística en Brasil. Según ellas, no dominar el portugués es la principal razón por la cual se sienten discriminadas. Para Borjas (1994), el dominio del idioma oficial de destino y la apropiación de habilidades lingüísticas constituyen una variable central en el análisis de las migraciones 
internacionales. Las entrevistadas afirman que los errores en el trabajo son generalmente atribuidos a ellas. El dominio de la lengua oficial es determinante para el proceso de inserción al mercado de trabajo y para facilitar la demanda de condiciones dignas en el país de destino. Según Benalcázar (2004), los inmigrantes colombianos adoptan el "hablar a lo ecuatoriano", es decir hacer uso de las formas verbales en pasivo o presente progresivo, buscando mascararse entre los nativos.

Las entrevistadas colombianas y paraguayas afirman que se sienten discriminadas por su estatus migratorio irregular. El $74 \%$ de las colombianas y un $75 \%$ das paraguayas se encontraban en situación administrativa irregular. El $26 \%$ das colombianas habían regularizado su situación como refugiadas, y declararon sentirse estigmatizadas por esa condición migratoria. El $25 \%$ de las paraguayas declararon encontrarse en situación administrativa regular.

\section{Gráfica 2. Comparación porcentual entre el estatus migratorio de colombianas y paraguayas}

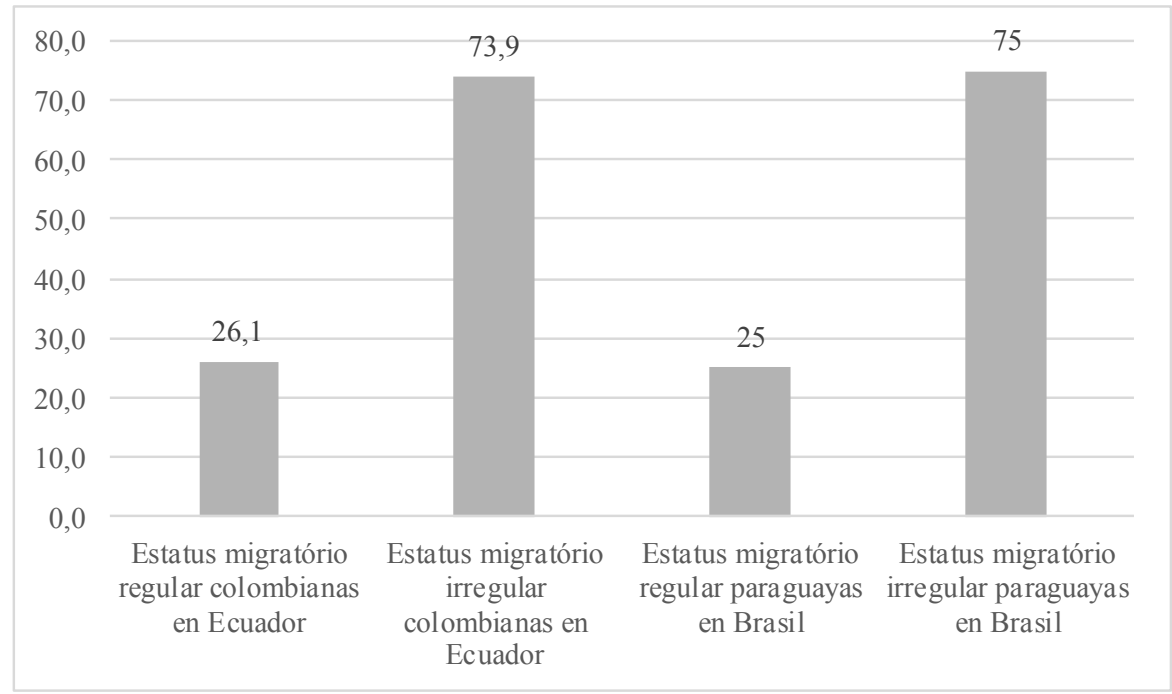

Fuente: elaboración propia a partir de las entrevistas

Entre las principales causas declaradas como justificación para la irregularidad migratoria citan los altos costos de los documentos y falta de información. Una paraguaya comentó que, durante el trámite de la visa, a pesar de ella y su esposo tener condiciones semejantes, la policía federal solamente regularizó la visa de él. Según ella, su esposo "tuvo suerte de ser atendido por un funcionario buena gente". Ese incidente revela que en algunos casos la discriminación es naturalizada entre quien la sufre. 
El estatus regular no es una condición común para las mujeres migrantes latinoamericanas que enfrentan escasos recursos materiales y baja cualificación profesional. De otro lado, los países de destino en el continente carecen de un marco jurídico y de políticas migratorias adecuadas a las necesidades de las mujeres inmigrantes, principalmente, aquellas inseridas en el mercado de servicios domésticos y de cuidados. Es alarmante, en el caso de las paraguayas en Brasil, que a pesar de tratarse de un flujo migratorio regulado por el Mercado Común del Sur (Mercosur) que garantizó el derecho de migrar de forma regular con un acuerdo de residencia, el alto índice de mujeres con estatus migratorio irregular.

El 35\% de las colombianas afirmaron tener un año o menos de permanencia en Ecuador. De otro lado, $35 \%$ de las migrantes paraguayas se consideraban "recién llegadas", es decir, con tiempo igual o menor a un año de permanencia en la ciudad de São Paulo. Colombianas y paraguayas afirmaron que se sienten discriminadas por ser inmigrantes. Colocaron como excepcional el hecho de encontrar "buenos patrones", es decir que respetan sus derechos. Habitualmente, la urgencia y necesidad de obtener ingresos condicionan a esas migrantes a desempeñar trabajos abusivos. Las paraguayas entrevistadas trabajan en la "feria de la madrugada", nombre que revela el inicio de la jornada de trabajo, a las 3 a.m. de lunes a sábado. El $50 \%$ das paraguayas trabajan como vendedoras, en jornadas de seis días por semana, aproximadamente 12 horas cada una (CSEM, 2014). Afirman sentirse sobrecargadas en relación a las actividades atribuidas a los trabajadores nativos, brasileños.

Colombianas y paraguayas afirmaron que la expectativa de conseguir empleo para contribuir con el ingreso familiar fue el motivo principal para migrar. $90 \%$ de las paraguayas declararon algún tipo de vínculo laboral en el sector de ventas o confección de vestuario. La inserción de las mujeres inmigrantes en el comercio informal, trabajo doméstico y el sector de servicios, en menor proporción, sugieren la segmentación femenina en la vigente división del trabajo.

El 26\% de las entrevistadas colombianas trabajaban, en 2012, como vendedoras ambulantes en Ecuador. Según Lyons (2004), los miembros de la familia participan de esa actividad, sin distinción de edad. En ese comercio se ofrecen alimentos, artesanías, productos de higiene y utilidades domesticas en general. Esa inserción marginal revela precarización del trabajo en relación a las actividades desempeñadas en el lugar de origen, como comercio formal, trabajadoras rurales y trabajo doméstico. $0,4 \%$ se encontraban en funciones equivalentes a las desempeñadas en origen y $1 \%$ en actividades con cierto grado de asenso ocupacional - atendimiento en bancos y servicios electrónicos. Esas actividades históricamente han sido desempeñadas por mujeres.

Un porcentaje de $92 \%$ de las entrevistadas colombianas afirman que solamente recomendarían migrar a quien tiene amenazas de muerte en el país de origen. Esa comprensión del proyecto migratorio coloca en relieve el carácter forzado de ese flujo migratorio. El $75 \%$ de las paraguayas encuestadas 
afirmaron que desanimarían a quien planee migrar. Esas respuestas remiten a un balance negativo de la experiencia migratoria que puede estar asociado a la interseccionalidad de la discriminación negativa sufrida por las inmigrantes en cuestión. El análisis de esas afirmativas evidenció que estigmas de género se yuxtaponen a prejuicios de nacionalidad, discriminación étnica-racial-lingüísticafenotípica y fobias asociadas a la condición jurídico-administrativa de esas mujeres inmigrantes.

\section{Conclusión}

Las vivencias de las inmigrantes colombianas y paraguayas permitieron avanzar en la identificación de situaciones cotidianas en las cuales experimentaron diferentes formas de discriminación negativa. El enfoque de la interseccionalidad en las migraciones femeninas es fundamental para destacar que las mujeres inmigrantes son vulnerables a discriminación de género (por ser mujer), discriminación racial y fenotípica (por su origen étnico-racial-nacional), discriminación de clase (por ser pobres), discriminación jurídica (por su estatus migratorio irregular) y discriminación lingüística (por no dominar el idioma oficial del país de destino). En el universo migratorio femenino, esas modalidades de discriminación se experimentan en yuxtaposición, es decir las inmigrantes sufren simultáneamente los diversos tipos de discriminación negativa.

La discriminación en contextos migratorios es un fenómeno de escala mundial observado en los países del norte y del sur global, aunque estos últimos reciban flujos migratorios de menor intensidad. Los postulados de las legislaciones internacionales que abarcan los diferentes tipos de discriminación son un avance importante en el sentido de sistematización del fenómeno. Sin embargo, los cambios que dichos tratados promueven aún deben ser alcanzados. Este artículo enfatizó los flujos de Colombia hacia Ecuador y Paraguay hacia Brasil. Ambos casos comportan semejanzas (flujos migratorios femeninos entre fronteras) y diferencias (migración económica y migración forzada). El análisis comparado permitió levantar elementos que pueden contribuir con la comprensión de la feminización de las migraciones entre países del sur global y destacar que las diferentes modalidades de discriminación negativa sufrida por las inmigrantes no se limitan a los países del norte.

Se buscó evidenciar, a partir de las respuestas de inmigrantes colombianas y paraguayas radicadas respectivamente en Ecuador y Brasil, semejanzas y diferencias sobre las percepciones de las inmigrantes ante los diferentes tipos de discriminación negativa. El estudio se apoyó en las afirmativas obtenidas mediante la aplicación de un cuestionario a 43 inmigrantes en contraste con la literatura específica. Al conferir centralidad a esas respuestas otorgó visibilidad a las mujeres inmigrantes, muchas de ellas anónimas y silenciadas.

El análisis aquí presentado permite afirmar que la migración es vivida como una estrategia orientada por el deseo de transformar condiciones de 
vulnerabilidad vivenciadas en los países de origen. En el caso de las paraguayas sobresalen motivaciones de carácter financiero, en las colombianas amenazas contra su vida. Sin embargo, las adversidades enfrentadas en los países de destino las hacen cuestionar el imaginario social sobre la eficacia de la migración internacional como alternativa para superar los dramas sociales que las motivaron a dejar sus locales de origen.

Las respuestas analizadas indican que la migración internacional agudizó dicha vulnerabilidad puesto que incorporó en su cotidiano además de la discriminación de género otras formas que aparecen yuxtapuestas con estereotipos en torno del fenotipo, del origen nacional, étnico, racial, lingüístico y fobias asociadas a su condición jurídico-administrativa en los países de destino. Ante la prevalencia de los diferentes tipos de discriminación urge una pedagogía de respeto a la diferencia y prevalencia de la dignidad de los seres humanos sin distingos de clase, género, raza, nacionalidad, estatuto jurídico, entre otras clasificaciones usadas en favor de la perpetuación de la injusticia social.

\section{Notas}

${ }^{1}$ Este trabajo se elaboró con apoyo de la línea de investigación “Mujer Migrante" promovida por el Centro Scalabriniano de Estudios Migratorios (CSEM).

${ }^{2}$ En esa investigación fueron entrevistadas inmigrantes radicadas en seis países: paraguayas en Brasil, brasileñas en Estados Unidos, haitianas en República Dominicana, colombianas en Ecuador, filipinas en Italia y nicaragüenses en Costa Rica. El objetivo de ese estudio fue destacar su protagonismo cada emprendimiento migratorio. Se avanzó en la identificación de dificultades cotidianas y de las estrategias utilizadas para su establecimiento en los países de destino. El trabajo de campo se realizó en el 2012 (CSEM, 2014).

${ }^{3}$ Esas ciudades pertenecen a las provincias de Pichincha, Imbabura, Sucumbius y Esmeraldas, respectivamente. Las cuatro provincias son próximas a la frontera con Colombia. Aproximadamente 150 kilómetros separan a Ipiales, ciudad fronteriza colombiana, de Quito.

4 Contrastando, la discriminación positiva se enfoca en aquellos que tienen menos oportunidades, buscando ofrecer acciones en favor de segmentos sociales carentes objetivando integrarlos al régimen de derechos.

${ }^{5}$ Todas las informaciones sobre las ratificaciones de los tratados están disponibles en: https:// treaties.un.org/doc/Publication/MTDSG/Volume\%20I/Chapter\%20IV/IV-8.en.pdf

Acceso en: 30.06.2015.

${ }^{6}$ Estas informaciones están disponibles en: http://www.ilo.org/dyn/normlex/en/f?p=NORMLEXPUB:11310:0::NO:11310:P11310_ INSTRUMENT_ID:312242:NO

Acceso en: 30.06.2015. 
${ }^{7}$ Argentina ocupa el primer lugar porque recibe 69\% y España el segundo lugar con un 23\% del total de inmigrantes paraguayos.

${ }^{8}$ Según Soto (2013), en Paraguay "Ia concentración de la tierra, el arrendamiento, la expulsión de los productores de sus lotes y la pulverización creciente de las pequeñas parcelas por efecto del crecimiento demográfico, junto con la producción para la subsistencia" (p. 88), agudizan la desigualdad social e incentivan las migraciones. $40,5 \%$ de la población se localiza en áreas rurales, calculada en 2.792 .873 habitantes, $52,8 \%$ hombres y $47,2 \%$ mujeres.

\section{Referências}

ACNUR. Desplazamiento. El nuevo reto del siglo XXI: Tendencias Globales 2012. Ginebra, 2013. Disponible en: http://www.acnur.org/t3/fileadmin/Documentos/Publicaciones/2013/9180.pdf?view Acceso en: 30.06.2015.

ARIZA, Marina. Migración y mercados de trabajo femeninos en el contexto de la globalización. Trabajadoras latinas en el servicio doméstico en Madrid y Nueva York. III Congreso de la Asociación Latinoamericana de Población. Córdoba, Argentina, 24-26 de septiembre de 2008.

Disponible en:

http://www.alapop.org/2009/images/DOCSFINAIS_PDF/ALAP_2008_FINAL_274.pdf Acceso en: 30.06.2015.

ASSIS, Gláucia de Oliveira; KOSMINSKY, Ethel V. Gênero E Migrações Contemporâneas. Estudos Feministas, Florianópolis, 15(3): 336-338, setembro-dezembro/2007.

BENALCÁZAR, Patricio. El refugio en el Ecuador. Quito: Cotopaxi, 2004.

BORJAS, George. J. The economics of immigration. Journal of Economic Literature, v. 32, n. 4, 1994, p. 1667-1717.

BOTEGA, Tuíla; RUANO, Elizabeth. A dimensão do retorno nas narrativas de migrantes paraguaias e brasileiras. In: VASCONCELOS, Ana Maria Nogales; BOTEGA, Tuíla (orgs.). Políticas públicas e o paradoxo da globalização. Porto Alegre: EDIPUCRS, Brasília: CSEM, 2015, p. $105-134$.

Disponível em: http://ebooks.pucrs.br/edipucrs/Ebooks/Pdf/978-85-397-0739-3.pdf Acesso em 08 mai. 2016.

CALAVITA, Kitty. Gender, Migration, and Law: Crossing Borders and Bridging Disciplines. International Migration Review, v. 40, n. 1, Gender and Migration Revisited, Spring, 2006, p. 104-132.

CASTEL, Robert. A Discriminação Negativa - Cidadãos ou Autóctones? Petrópolis: Vozes, 2008.

CEDAW. General recommendation No. 26 on women migrant workers. CEDAW/C/2009/ WP.1/R. 5 December 2008.

Disponible en:

http://www2.ohchr.org/english/bodies/cedaw/docs/GR_26_on_women_migrant_workers_ en.pdf

Acceso en 03.07.2015. 
CORTES, Tiago; FREIRE DA SILVA, Carlos. Migrantes na costura em São Paulo: paraguaios, bolivianos e brasileiros na indústria de confecções. Travessia, v. XXVII, n. 74, jan.jun./2014, p. 37-58.

CRENSHAW, Kimberle W. A interseccionalidade na discriminação de raça e gênero. Painel 1. Cruzamento: raça e gênero. Brasília: Unifem, 2004.

Disponible em:

http://www.acaoeducativa.org.br/fdh/wp-content/uploads/2012/09/KimberleCrenshaw.pdf

Acceso en: 18.06.2015.

CSEM. Relatório de pesquisa Mulher migrante: agente de resistência e transformação. Brasília: CSEM. 2014. 112 p.

DUTRA, Delia. Mulheres do sul também migram para o sul, paraguaias no Brasil. Anuario Americanista Europeo, n. 11, 2013a, p. 93-108.

. Mulheres, migrantes, trabalhadoras: a segregação no mercado de trabalho. REMHU: Rev. Interdiscip. Mobil. Hum., v. 21, n. 40, Jan./jun. 2013b, p. 177-193.

Mulheres migrantes peruanas em Brasília: o trabalho doméstico e a produção do espaço na cidade. Tese de Doutorado defendida no Departamento de Sociologia. Universidade de Brasília. Brasília, 2012.

GUTIÉRREZ, Héctor. Fobias múltiples y discriminación. Obstáculos en las luchas por la dignidad. In: CAROSIO, Alba. BANKO, Catalina. PRIGORIAN, Nelly (org.). América Latina y el Caribe: Un continente, múltiples miradas. Buenos Aires: CLACSO, 2014.

ILO; IOM; OHCHR. International Migration, Racism, Discrimination and Xenophobia. August 2001.

Disponible en: http://www.unesco.org/most/migration/imrdx.pdf Acceso en 03.07.2015.

LOPES, Cristiane. O direito a não discriminação dos estrangeiros. Boletim Científico ESMPU, a. 11, n. 37, Edição Especial 2012, p. 37-61.

LYONS, Kristina. Vendedores ambulantes en Ibarra: el sector informal en refugio. In: BENALCÁZAR, Patricio. El refugio en el Ecuador. Quito: Cotopaxi. 2004.

MORALES, Abelardo; LI WING-CHING, Karina; ACUÑA, Guillermo. Migración y salud en zonas fronterizas: Colombia y el Ecuador. Santiago de Chile: Cepal. 2010. 67 p.

OIM. Datos sobre Migración Colombiana.

Disponible en:

http://www.oim.org.co/migracion-colombiana/datos-sobre-migracion-colombiana.html Acceso en: 03.07.2015.

OIM. Perfil Migratorio de Paraguay. 2011.

Disponible en:

http://publications.iom.int/bookstore/free/PerfilMigratoriodeParaguay.pdf

Acceso en: 02.07.2015.

ONU. Convención internacional sobre la protección de los derechos de todos los trabajadores migratorios y de sus familiares. Genebra. Adoptada por la Asamblea General en su resolución 45/158, de 18 de diciembre de 1990.

Disponible en: http://www.ohchr.org/SP/Professionallnterest/Pages/CMW.aspx

Acceso en: 18.06.2015. 
ONU. Convención Sobre el Estatuto de Los Refugiados. Adoptada en Ginebra, Suiza, el 28 de julio de 1951 por la Conferencia de Plenipotenciarios sobre el Estatuto de los Refugiados y de los Apátridas. Genebra: Nacões Unidas, 1951.

Disponible en:

http://www.acnur.org/t3/fileadmin/scripts/doc.php?file=t3/fileadmin/Documentos/ BDL/2001/0005

Acceso en: 18.06.2015

ONU. Convención Sobre La Eliminación De Todas Las Formas de Discriminación Contra La Mujer. Genebra: Nações Unidas, 1979.

Disponible en: http://www.un.org/womenwatch/daw/cedaw/text/sconvention.htm Acceso en: 18.06.2015.

ONU. Convenio relativo a los trabajadores migrantes. Genebra: Nações Unidas, 1949. (revisado en 1949) (Entrada en vigor: 22 enero 1952).

Disponible en:

http://www.ilo.org/dyn/normlex/es/f?p=NORMLEXPUB:12100:0::NO::P12100_ INSTRUMENT_ID:312242

Acceso en: 18.06.2015.

ORTIZ, Diana; KAMINKER, Sergio. Suramérica y los refugiados colombianos. REMHU: Revista Interdisciplinar da Mobilidade Humana, v. 22, n. 43, jan./jun. 2015, p. 35-51.

PARAGUAI. Anuário Estadístico del Paraguay 2011. Asunción: Dirección general de estadística, encuestas y censos (DGEEC), 2013. 388 p.

PARELLA, Sonia. Mujer, inmigrante y trabajadora: la triple discriminación. Barcelona: Anthropos, 2003.

. Segregación laboral y 'vulnerabilidad social' de la mujer inmigrante a partir de la interacción entre clase social, género y etnia. In: FLAQUER, Luís; SOLÉ, Carlota. El uso de las políticas sociales por las mujeres inmigrantes. Madrid: Ministerio de Trabajo y Asuntos Sociales. Instituto de la Mujer, 2005.

PERARO, Maria Adenir. A imigração para Mato Grosso no século XIX - Mulheres paraguaias: estratégias e sociabilidades. Revista Territórios e Fronteiras, v. 2, 2003, p.121-134.

PROFIT. Alena. El hombre soy yo: dinâmicas familiares no contexto da imigração paraguaia ao Brasil. Brasília: dissertação de mestrado CEPPAC/UnB, 2015.

SALA, Gabriela Adriana. Características demográficas e sócio ocupacionais dos migrantes nascidos nos países do Cone Sul residentes no Brasil. Tese de Doutorado defendida no Departamento de Demografia, Universidade Federal de Minas Gerais, Belo Horizonte. 2005. 243p.

SÁNCHEZ, Marco; HERNÁNDEZ, Luis; PÉREZ, Gerardo. Acercamiento teórico al fenómeno de la discriminación. In: SÁNCHEZ, Marco; HERNÁNDEZ, Luis; PÉREZ, Gerardo. Un acercamiento a la discriminación. De la teoría a la realidad en el estado de México. Toluca: CDH. 2007, $304 \mathrm{p}$.

SOTO, Lílian. Las mujeres y la tierra en Paraguay. In: DOBREE, Patricio. (Org.). La tierra en el Paraguay: de la desigualdad al ejercicio de derechos. Asunción: Programa Democratización y Construcción de la Paz - Paraguay, 2013. 
UNITED NATIONS. The number of international migrants worldwide reaches 232 million. Population facts. No. 2013/2, September 2013.

Disponible en:

http://esa.un.org/unmigration/documents/the_number_of_international_migrants.pdf Acceso en 02.07.2015

VILELA, Elaine. M. Desigualdade e discriminação de imigrantes internacionais no mercado de trabalho brasileiro. Dados -Revista de Ciências Sociais, v. 54, n. 1, 2011, p. 89-129.

VILELA, Elaine; NORONHA, Cláudia. Trabalhadoras argentinas, bolivianas, paraguaias, peruanas e uruguaias: minorias étnicas/nacionais discriminadas no Brasil? In: XXIX Congresso ALAS. Santiago. 2013.

Disponible en:

http://actacientifica.servicioit.cl/biblioteca/gt/GT8/GT8_MeireViela_LimadeNoronha. pdf

Acceso en 02.07.2015

ZAVATTIERO, Claudina. Peculiaridades de la migración internacional y tendencias recientes (2009-2011): el Paraguay exporta carne, soja y jóvenes. Asunción: UNFPA, 2013. 104 p. Disponible en:

http://www.unfpa.org.py/download/documento_11_UNFPA.pdf Acceso en 03.07.2015. 


\title{
RESUMEN
}

A partir de las respuestas de migrantes colombianas y paraguayas radicadas en Ecuador y Brasil respectivamente $y$, en perspectiva con las disposiciones de los tratados internacionales, se objetiva analizar la yuxtaposición de formas de discriminación negativa, género, nacionalidad, lingüística, étnico-racial y estatus migratorio. La intersección analítica entre esas afirmativas y los dispositivos internacionales contra la discriminación, de los cuales son signatarios los cuatro países aquí analizados, ratifica la distancia entre los postulados de esas normativas internacionales y la situaciones cotidianas de discriminación que obstaculizan la inserción digna de las inmigrantes en los países de destino.

Palabras clave: discriminación negativa, inmigrantes paraguayas e inmigrantes colombianas.

\begin{abstract}
With the study of the narratives of Colombian and Paraguayan female migrants residents in Ecuador and Brazil respectively and the provisions of international treaties, this article aims to analyze the juxtaposition of different forms of negative discrimination: gender, nationality, linguistic, ethnic-racial and migratory status. The analytical intersection of those narratives and the international mechanisms against negative discrimination, which the four countries presented here are signatories, confirms that these international standards have not yet disrupted everyday situations of discrimination.
\end{abstract}

Key words: negative discrimination, colombian migrants, paraguayan migrants. 